\title{
The correlation between the physical power of golf players and the Titleist Performance Institute Level 1 test
}

\author{
Jaeeun $\mathrm{Kim}^{\mathrm{a}}$, Jongeun $\mathrm{Yim}^{\mathrm{b}}$, Kwangsun $\mathrm{Do}^{\mathrm{c}}$ \\ ${ }^{a}$ Department of Physical Therapy, Barosun Hospital, Seoul, Republic of Korea \\ ${ }^{b}$ Department of Physical Therapy, College of Health Science and Social Welfare, Sahmyook University, Seoul, Republic of Korea \\ 'Department of Physical Therapy, International St. Mary's Hospital, Catholic Kwandong University, Incheon, Republic of Korea
}

Objective: This was a correlation study for predicting the power to improve the distance of golf players and developing an effective power program.

Design: Cross-sectional study.

Methods: The subjects of this study were 24 healthy males and females in their 20s and 30s who were golf athletes living in Seoul and Gyeonggi-do. In the Titleist Performance Institute (TPI) Level 1 test, the twelve swing characteristics include components of stability, mobility, body conditioning ability, and balance. The power test consisted of a vertical jump (VJ) in order to examine the power of the lower body, the seated chest pass (SCP) was used to examine upper body power, and the sit up and throw (SUAT) was used to examine the power of the upper body and core for the TPI Level 2 test.

Results: The results of this study showed that the 90/90 was correlated with VJ, SUAT, and SCP scores $(p<0.05)$. Single leg stance was correlated with VJ, SUAT, over head deep squat, and bridge with leg extension were correlated with VJ $(p<0.05)$. The toe touch was correlated with SUAT results $(p<0.05)$.

Conclusions: The results of this study showed that the TPI Level 1 test and power test were correlated with the performance of the golf players. Future studies have shown that fitness program development and further research are needed.

Key Words: Golf, Mechanics, Power, Prevention \& control, Range of motion

\section{Introduction}

In the Republic of Korea, golf is a sport with a high level of interest, especially due to the high ranking of the international stage of female professional golfers, and the distance and accuracy of the driver are very important variables in ranking [1]. Among them, driver distance can be considered as an important predictor of an elite golfer's performance [2]. In fact, among the 2016 Professional Golfers' Association Tour winners in 2016, including Dustin Johnson, Justin Thomas, John Rahm, Bubba Watson, and Hideki Matsuyama (http://www.pgatour.com/), the driver distance was more than 300 yards. To increase distance, swing technique, shaft, head, and individual power can be considered as influential variables [3]. However, in recent years, golf fitness and training with more flexibility and strength training have been shown to improve golf performance and distance more effectively [4-6]. This is because the golf swing is a complex movement caused by joints and muscles throughout the body, rather than just being forced by the golf equipment to the ball [7]. Such fitness training is ultimately important for injury prevention and rehabilitation of the golf player [8], and contributes to maintaining a high level of playability [9], which is an effective way to increase club head speed and distance by improving muscle mobilization sequence during swing [10]. In order to increase the performance and power

Received: 18 December, 2017 Revised: 4 March, 2018 Accepted: 12 March, 2018

Corresponding author: Jongeun Yim (ORCID http://orcid.org/0000-0001-7510-8233)

Department of Physical Therapy, College of Health Science and Social Welfare, Sahmyook University, 815 Hwarang-ro, Nowon-gu, Seoul 01795, Republic of Korea

Tel: 82-2-3399-1635 Fax: 82-2-3399-1639 E-mail: jeyim@syu.ac.kr

(c) This is an Open-Access article distributed under the terms of the Creative Commons Attribution Non-Commercial License (http://creativecommons.org/licenses/ by-nc/4.0) which permits unrestricted non-commercial use, distribution, and reproduction in any medium, provided the original work is properly cited.

Copyright $\odot 2018$ Korean Academy of Physical Therapy Rehabilitation Science 
of the body, the focus is mainly on skill, and the kinetic chain, including the body's neurological and epidemiological ability, is not realized properly [11]. The most important reason is that the human movement undergoes an efferent process called the central nervous system based on sensory information and information, and an integrated motion. The afferent information is interdependent by three factors: physiological, biomechanical, and neuromuscular [12]. Therefore, there is a limit to existing skills in the performance of golf players.

Recently, Titleist Performance Institute (TPI) has developed golf, medical, and fitness. Through these assessments, we identify strength, flexibility, and balance to find and solve common swing problems [4]. The TPI Level 1 tests to see the body's mobility and stability in 16 tests, the TPI power test is used to see the power of the body, and video and the Selective Functional Movement Assessment specifically identifies pain and body restriction during swing [13]. Despite the development of these programs, however, there is a lack of evidence for various effects. According to Gulgin et al. [4], Kim and Park [5], and Torres-Ronda et al. [6], physical strength and endurance-related physical abilities are highly correlated with power, but they lack simple and influential connectivity and fitness programs.

Therefore, the purpose of this study was to compare the TPI Level 1 test with physical power and to improve and predict the effective physical power of the athlete.

\section{Methods}

\section{Subjects}

The subjects of this study were 24 healthy males and females in their 20s and 30s who were golf athletes living in Seoul and Gyeonggi-do. The subjects did not have any physical impairments or potential for impairments in the TPI Level 1 and power test. All subjects voluntarily agreed to the test and also provided written informed consent prior to study enrollment. This study was approved by the Institutional Review Board of the Sahmyook University (IRB No. 2-1040781-AB-N-01-2018008HR).

\section{Measurement}

\section{TPI Level 1 test}

In the TPI Level 1 test, each of the twelve motion screenings assessed stability, mobility, body conditioning ability, and balance in the addressing posture (Figure 1). The twelve movements included the pelvic tilt test, pelvic rotation test, trunk rotation test, overhead deep squat (ODS) test, toe touch (TT) test, 90/90 test, single leg stance (SLS) test, and Latissimus dorsi test. In addition, the thoracic spine rotation on sitting, bridge with leg extension (BWLE) test, cervical rotation test, forearm rotation test, wrist hinge test, the wrist flexion test and lift-and-roll test were also assessed (Table 1) [4].

\section{Power test}

Power test consisted of a vertical jump (VJ) test to examine the power of the lower body, the seated chest pass (SCP) to examine upper body power, and sit up and throw (SUAT) test to examine the power of the upper body and core during the TPI Level 2 test. All values were performed three times and the highest values were recorded.

\section{Vertical jump}

The VJ test is a test that measures the overall leg power. From the standing position, the subject had to jump up and attempt to touch the wall at the highest point of the jump. Standard values are 17 inches for men and 15 inches for women.

\section{Seated chest pass}

This test measures the power of the upper body, especially the chest muscles and the deltoids. In a seated posture with a chair rest, the subject holds a Medicine ball (4 or $2 \mathrm{~kg}$ ) that is $5 \%$ of their weight their chest with both hands and send it as far away as possible with a chest pass. Standard values are 18 feets for men and 16 feets for women.

\section{Sit up and throw}

This is a test to measure abdominal and Latissimus dorsi muscle power. The sit-up motion itself can measure the pow-

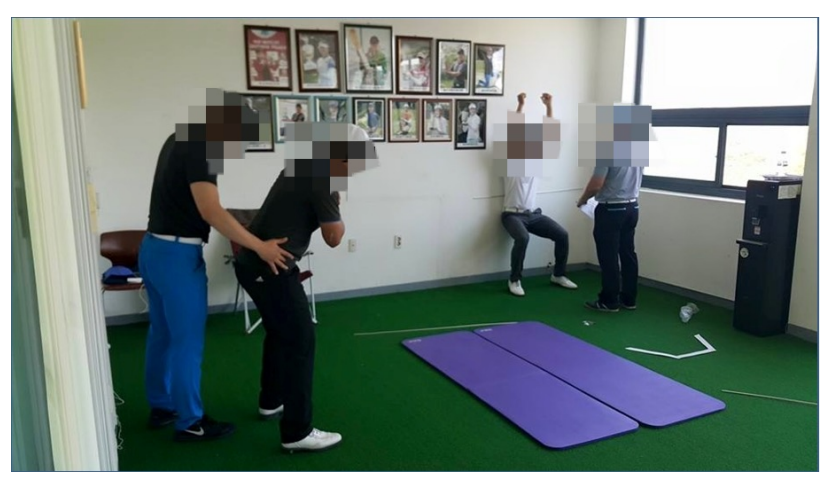

Figure 1. Titleist Performance Institute Level 1 test. 
Table 1. Details of TPI Level 1 test

\begin{tabular}{|c|c|}
\hline TPI Level 1 & Explanation \\
\hline Pelvic tilt test & Check the flexibility of the hip and back and check how well you are adjusting your posture. \\
\hline Pelvic rotation test & $\begin{array}{l}\text { Pelvic rotation test verifies the ability of a player to rotate the lower body independently of the } \\
\text { upper body. }\end{array}$ \\
\hline Upper body rotation test & $\begin{array}{l}\text { Upper body rotation test identifies the ability of the upper body to move independently of the lower } \\
\text { body. }\end{array}$ \\
\hline Overhead deep squat test & $\begin{array}{l}\text { Overhead deep squat test is the most informative test that hip, knee and ankle mobility, symmetry, } \\
\text { thoracic spine, shoulder flexion and abduction. }\end{array}$ \\
\hline Toe & Toe-touch testing checks the overall operability of back and hamstring. \\
\hline 90/90 test & 90/90 test checks the mobility of upper extremity, scapula, and stability of \\
\hline Single leg stance test & Single leg stance test is performed to measure the overall balance of the athlete. \\
\hline Lower limb rotation test & $\begin{array}{l}\text { Lower limb rotation test considers the rotation of the hip, tibia, and foot in the golf swing. } \\
\text { Sufficient rotation of the lower limb affects weight transfer and support. }\end{array}$ \\
\hline Cerv & This test examines the rotation and lateral flexion of the cervical vertebrae. \\
\hline Wrist hinge test & $\begin{array}{l}\text { It is a flexibility test that examines the flexion of the radioulnar of wrist. Flexibility of the wrist is } \\
\text { essential to properly release the golf club and generate power. }\end{array}$ \\
\hline Forearm rota & $\begin{array}{l}\text { It is a test that examines the flexibility of the forearm through wrist supination and pronation. Also, } \\
\text { flexibility of the forearm is essential to properly release the golf club and generate power. }\end{array}$ \\
\hline Wrist flexion test & $\begin{array}{l}\text { Wrist flexion test examines the ability to bend the wrist forward, affecting the downswing and } \\
\text { backswing. }\end{array}$ \\
\hline Latissimus dorsi test & $\begin{array}{l}\text { This test is carried out by leaning against the wall to see the shortening of the Latissimus dorsi, and } \\
\text { shortening of Latissimus dorsi can put a stress on the back in the swinging motion of the arm. }\end{array}$ \\
\hline Reach roll 1 & This test is a test to determine the flexibility of the lower trapezius and shoulder area. \\
\hline Thoracic rotation test on sitting & $\begin{array}{l}\text { This test is a test to determine the flexibility of the thoracic lumbar spine. Separation of the upper } \\
\text { and lower body in golf is essential for the speed and stable posture in the golf swing. }\end{array}$ \\
\hline Bridge with leg extension test & $\begin{array}{l}\text { This test examines the stability of the pelvis, lumbar vertebrae and cores. If this test is not } \\
\text { performed well, it may cause problems with the stability of the lower body during swing. }\end{array}$ \\
\hline
\end{tabular}

er of the core, and the head-throwing motion can measure the Latissimus dorsi and body power. The knees are bent and are feet flat on the floor in the lying position. The subject uses a medicine ball ( 4 or $2 \mathrm{~kg}$ ) that is $5 \%$ of their body weight and place the ball directly over head of subject, like a soccer throw-in motion. The subject must send away the ball as far as possible. The subject throws from the position where the ball first touches the floor and measures the distance to the chest in the sitting position. Standard values are 18 feets for men and 16 feets for women.

\section{Statistical methods}

Pearson correlation analysis was performed to examine the correlation between TPI tests (TPI Level 1, TPI power). Statistical significance was obtained when the $p$-value was less than 0.05. All statistical analyzes were performed using SPSS ver. 12.0 (SPSS Inc., Chicago, IL, USA).
Table 2. Correlation coefficients between total TPI Level 1 test and TPI power test

\begin{tabular}{cccc}
\hline Parameter & $\begin{array}{c}\text { Vertical } \\
\text { jump }\end{array}$ & $\begin{array}{c}\text { Sit up } \\
\text { and throw }\end{array}$ & $\begin{array}{c}\text { Seated } \\
\text { chest pass }\end{array}$ \\
\hline TPI Level 1 & 0.341 & 0.006 & 0.185 \\
\hline
\end{tabular}

TPI: Titleist Performance Institute.

\section{Results}

\section{TPI power and TPI Level 1 (Total score) test}

The correlation coefficient between VJ and TPI Level 1 was 0.341 with a significance level of $0.111(p<0.05)$. The correlation coefficient between the SUAT test and TPI Leve1 was 0.006 with a significance level of $0.977(p<0.05)$ and 0.185 between the SCP and TPI Level 1 with a significance level of $0.387(p<0.05)$, which showed no significant correlation (Table 2 ).

\section{VJ, SUAT, SCP, and TPI Level 1 test (Each score)}

First, the VJ had the highest correlation. The correlation 
Table 3. Correlation coefficients between SLS, ODS, BWLE, TT, and power test

$(\mathrm{N}=24)$

\begin{tabular}{lccccc}
\hline & $90 / 90$ & SLS & ODS & BWLE & TT \\
\hline VJ & $0.421(0.045)^{*}$ & $0.618(0.002)^{*}$ & $0.541(0.008)^{*}$ & $0.465(0.025)^{*}$ & $0.221(0.310)$ \\
SUAT & $0.433(0.039)^{*}$ & $0.374(0.078)$ & $0.341(0.111)$ & $0.343(0.109)$ & $0.314(0.144)$ \\
SCP & $0.567(0.004)^{*}$ & $0.475(0.019)^{*}$ & $0.394(0.057)$ & $0.188(0.380)$ & $0.560(0.004)^{*}$ \\
\hline
\end{tabular}

SLS: single leg stance, ODS: overhead deep squat, BWLE: bridge with leg extension, TT: toe touch, VJ: vertical jump, SUAT: sit up and throw, SCP: seated chest pass. ${ }^{*}<<0.05$.

coefficient for $\mathrm{VJ}$ and $90 / 9$ was 0.421 with a significance level of $0.045(p<0.05), 0.618$ for SLS with a significance level of 0.002 , and 0.541 for ODS with a significance level of $0.008(p<0.05), 0.465$ for BWLE with a significane level of $0.025(p<0.005)$.

Second, the SUAT and 90/90 had a correlation coefficient of 0.433 and a significance level of $0.039(p<0.05)$.

The correlation coefficient for SCP and $90 / 90$ was 0.567 with a significance level of $0.004(p<0.05), 0.475$ for SLS (Table 3).

\section{Discussion}

Upper body and lower body strength, flexibility and balance ability of a golf player influences power and timing in the golf swing [14]. This balanced physical ability can be said to be fundamental to improving distance [2].

Previous studies have shown that muscle in the correct sequence and optimum conditions affect the golfer's club head speed and distance [10]. Power of the trunk and abdomen represents endurance in the golf swing $(\mathrm{r}=0.38, p=0.04)$. The muscular strength of the outer and inner radial muscles greatly affects the distance of the female golfer in particular.

VJs were found to affect ball speed $(\mathrm{r}=0.57, p=0.02)$ and distance $(\mathrm{r}=0.61, p=0.01)$. The push-up, which indicates the power of the upper body, affects ball speed $(\mathrm{r}=0.48, p=0.05)$ and distance $(\mathrm{r}=0.61, p=0.01)$ [2].

Although it is not an exact evaluation of the behavior of previous studies, we can see how much power the upper body, lower body power, and trunk can have on distance.

\section{0/90 test}

This test was correlated with VJ representing lower body power, SUAT representing body power, and SCP representing upper body power. Therefore, the 90/90 test is one of the most essential elements for the upper body, lower body, and trunk of the golf player's physical power.

\section{SLS test}

This test correlated with $\mathrm{VJ}$, which represents lower body power, and SCP, which represents upper body power. Therefore, SLS is one of the most essential elements for lower body and upper body of golf player's physical power. Previous studies also reported a positive correlation between the VJ and SLS ( $\mathrm{r}=0.618, p=0.002)[15,16]$. Also, SLS is a common body limitation for golfers, and more skilled golfers are better able to perform SLS than the less skilled golfers [17]. If not, the right-handed golfer shows instability of the left-handed leg [4].

\section{ODS test}

This test correlated with VJ, which represents the lower body power. Therefore, ODS is one of the essential elements of lower body power the golfer.

\section{BWLE test}

In this study, the BWLE correlated with $\mathrm{VJ}$, which represents lower body power. Therefore, it can be seen that BWLE is one of the essential elements for the physical power of the lower body of the golfer.

\section{TT test}

This test correlated with SCP, which represents the power of the trunk. Therefore, TT is one of the most essential elements for the trunk of the golf player's physical power.

As stated in introduction, the bodies have interdependent relations. Joints have two tendencies and participate in body movements; there are mobility joints and stability joints. Mobility joints correspond to the shoulder, hip, thoracic spine, upper cervical vertebra, and ankle. Stability joints are the lower cervical spine, scapula, lumbar spine, and knee. If the joint is doing something that does not fit the tendency, the body may move in an unnatural manner in any motion. The results of this study can also be explained based on the 
theory of joint by joint of Gray Cook. The physical abilities of each joint may have influenced each corresponding power action. Therefore, attention should be placed on adjusting the ability of each joint before power training [11].

In the TPI Level 1 test, the ODS, TT, SLS, and BWLE were the most frequent test used in golfers [4]. In this study, the limitations of the over head deep squat $(91.7 \%)$, lower quadrant rotation (87.5\%), and 90/90 (79.2\%) were different between other studies. The 90/90 of the TPI Level 1 test, SLS, ODS, BWLE, and TT were correlated with power and was correlated with three types of VJ, SUAT, SCP, jump, SUAT, ODS, and BWLE correlated with VJ. The TT correlated with SUAT. Therefore, having good shoulder mobility and stability, hip and core mobility and stability, hip and hamstring flexibility should be considered as a necessity for improving the power in golfers.

Among the various fields of golf, distance is an essential element in order to be a top ranker, and the body's power ability is the most important factor to increasing distance.

In recent years, there has been a growing interest in improving the condition and physical abilities of athletes through fitness programs in addition to golf skills by teaching professionals, but there is a lack of proper program development. The purpose of this study was to develop an effective prediction and program for power increase. The results of this study showed that the TPI Level 1 test and power test were correlated to the performance of the golf player. The 90/90 was correlated with the VJ, SUAT, SCP, and SUAT were correlated, and ODS and BWLE correlated with the VJ. The TT correlated with the SUAT. Future research should focus more on the development of fitness programs such as these.

\section{Conflict of Interest}

The authors declared no potential conflicts of interest with respect to the authorship and/or publication of this article.

\section{References}

1. Hume PA, Keogh J, Reid D. The role of biomechanics in max- imising distance and accuracy of golf shots. Sports Med 2005; 35:429-49.

2. Wells GD, Elmi M, Thomas S. Physiological correlates of golf performance. J Strength Cond Res 2009;23:741-50.

3. Fletcher IM, Hartwell M. Effect of an 8-week combined weights and plyometrics training program on golf drive performance. $\mathrm{J}$ Strength Cond Res 2004;18:59-62.

4. Gulgin HR, Schulte BC, Crawley AA. Correlation of Titleist Performance Institute (TPI) level 1 movement screens and golf swing faults. J Strength Cond Res 2014;28:534-9.

5. Kim KJ, Park DH. Comparative analysis of physical fitness and relationship of driver distance and average score in general, national and pro female golf players. Exerc Sci 2015;24:305-13.

6. Torres-Ronda L, Delextrat A, González-Badillo JJ. The relationship between golf performance, anthropometrics, muscular strength and power characteristics in young elite players. Int Sport Med J 2014;15:156-64.

7. McHardy A, Pollard H. Muscle activity during the golf swing. $\mathrm{Br}$ J Sports Med 2005;39:799-804; discussion 799-804.

8. Grimshaw P, Giles A, Tong R, Grimmer K. Lower back and elbow injuries in golf. Sports Med 2002;32:655-66.

9. McHardy A, Pollard H, Luo K. Golf injuries: a review of the literature. Sports Med 2006;36:171-87.

10. Doan BK, Newton RU, Kwon YH, Kraemer WJ. Effects of physical conditioning on intercollegiate golfer performance. J Strength Cond Res 2006;20:62-72.

11. Cook G. Movement: functional movement systems: screening, assessment, corrective strategies. Aptos, CA: On Target Publications; 2010 .

12. Frank CC, Lardner R, Page P. Assessment and treatment of muscle imbalance: the Janda approach. Champaign, IL: Human Kinetics; 2010.

13. Rose G. TPI CERTIFIED. In golf fitness instructor seminar manual 2007.

14. Nesbit SM, Serrano M. Work and power analysis of the golf swing. J Sports Sci Med 2005;4:520-33.

15. Okada T, Huxel KC, Nesser TW. Relationship between core stability, functional movement, and performance. J Strength Cond Res 2011;25:252-61.

16. Bird SP, Barrington-Higgs B, Hendarsin F. Relationship between functional movement screening and physical fitness characteristics in Indonesian youth combat sport athletes. Paper presented at: 4th Exercise and Sports Science Australia Conference; 2010 Apr 9-11; Gold Coast, QLD, Australia.

17. Sell TC, Tsai YS, Smoliga JM, Myers JB, Lephart SM. Strength, flexibility, and balance characteristics of highly proficient golfers. J Strength Cond Res 2007;21:1166-71. 